\title{
ARISTOTELIAN MISTAKES
}

In his book Roman Law: Linguistic, Social and Philosophical Aspects (Edinburgh, 1969), Professor Daube proposes a heterodox interpretation of Aristotle's distinction

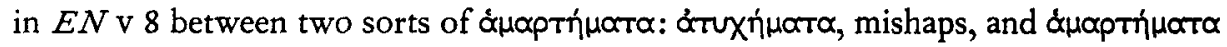
proper, mistakes. Mr Crook, in his review of the book ( $C R$ n.s. Xx (1970), ${ }_{3} \sigma_{3}$ ), has already taken issue with the main point of this interpretation. In what follows I hope to clinch the verdict for orthodoxy, whileceding to Daube a point of broader significance.

Aristotle characterizes \&̊র́p we might say, by one private person against another), involving ignorance on the agent's part about some particular circumstance of his action ( I I 35 b i I-16). He calls this class of injury ámópтnua because he holds that inasmuch as the agent did not know what he was doing, to that extent he did not mean to do what he did (cf. I 135 a 23-32). The distinction within the class which is our concern is presented in these terms:

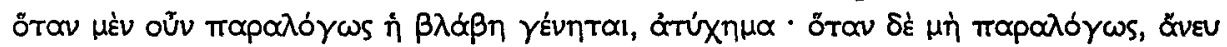

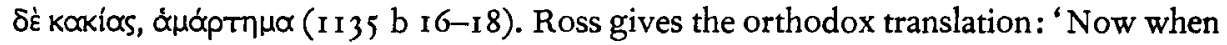
the injury takes place contrary to reasonable expectation, it is a misadventure. When it is not contrary to reasonable expectation, but does not imply vice, it is a mistake.' Daube's contention is that it is wrong to render mapoió $\gamma \omega$ s as 'contrary to reasonable expectation'. He thinks this rendering reflects a long tradition of misinterpretation in which Aristotle's text has been understood with the aid of inappropriate categories of liability drawn from Roman law (pp. 131-56). His quarrel is with 'reasonable'. Aristotle's distinction is, he believes, based solely on a question of psychological fact, not at all on any consideration of what the agent might have been expected to foresee (e.g. pp. 132-4, 144-5).

The principal argument Daube brings against the usual translation is that in this passage (and in related passages in the Rhetoric I I 3. $1374 \mathrm{~b} 2 \mathrm{ff}$. and the un-Aristotelian Rhetoric to Alexander 1427 a $23 \mathrm{ff}$.) there is in the context no play with concepts like care, negligence, and the like. It is rather ignorance which is invoked in characterization and explanation (e.g. pp. 132-4, I40-2). Now whether this observation of Daube's is sound is a question to which we shall return in due course. For the present we should notice that the considerations of context he adduces make in any event an

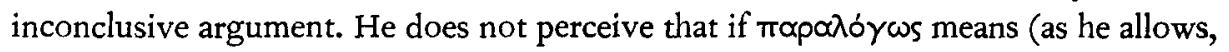
p. 144) 'contrary to calculation', it may conceivably have the force 'contrary to any reasonable calculation' (as distinct from 'contrary to what $X$ calculated') even when talk of care or negligence is absent. Nor does Aristotle's stress on the ignorance in-

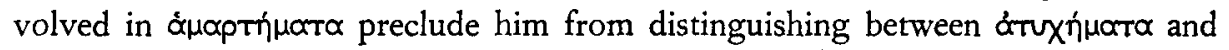
\&uवpтría $\alpha$ proper in the way he has usually been thought to do. Even if such injuries are most importantly characterized as the results of actions which their agents would not have performed had they known the crucial facts they were ignorant of, that is no reason why Aristotle could not still find it worth distinguishing between cases where the agent might reasonably have been expected to foresee such an unhappy outcome and others where he might not. His main aim is to mark off the class 
of unintentional injuries. But once that is done, he can turn to make differentiations within the class on a quite different basis from that on which he establishes it as a class.

What considerations ought we to allow to decide us on Aristotle's meaning, then?

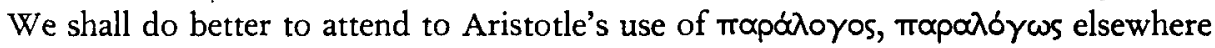
(which Daube fails to do) and to the philosophical merits of the rival interpretations of the word in the sentence which concerns us (as Daube does - if he does - much too hastily, as we shall see).

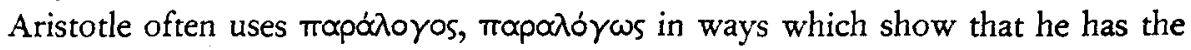
notion contrary to reason in mind (cf. Bonitz, Index Aristotelicus 565 a 48-5I). This is pre-eminently the case when he applies the word to luck, as here. In his essay on

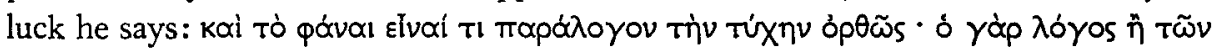

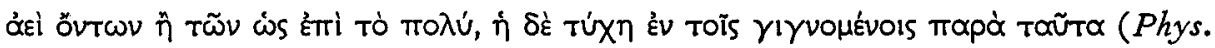

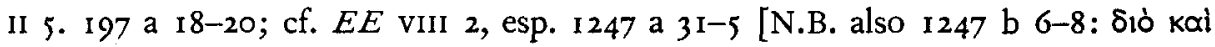

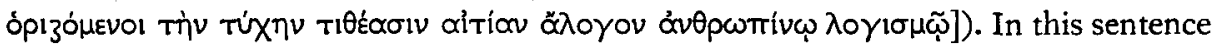

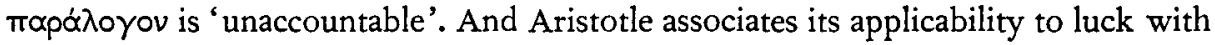
an entirely objective feature of lucky events, not with the psychological states of an individual agent. The mere similarity between what he says there and his specification

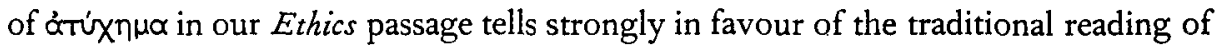
that passage. If we were to press the connection, we could say that in the Physics

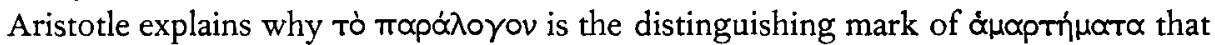
are ớtuxinuoro which he claims it to be in the Ethics.

The task of assessing the philosophical advantages and drawbacks of Daube's attempt to remove 'reasonable' from the translation of $\pi \propto p \propto \lambda$ ó $\gamma \omega s$ is complicated by his extremely elastic statements of his own interpretation of the Greek. Although $\mu \eta \dot{\eta}$ maporió $\gamma \omega$ s is first rendered as 'not unexpectedly' (p. 133), this is quickly glossed as 'you intend it' (ibid.; cf. p. I 4I), which in turn is paraphrased as 'by no means unlooked for' (p. I44) and 'according to plan' (p. 149).

The least objectionable interpretation of Daube's position is the one he himself does not, it seems, really want to adopt. According to this construction of the Greek,

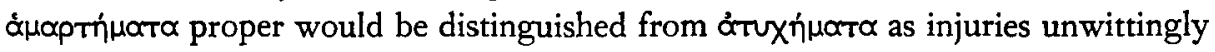
brought about by a man's action not contrary to what he actually expected or calculated, yet without vice. There are two principal difficulties entailed by it: the criterion it imputes to Aristotle demarcates the class of mistakes proper in an arbitrary way; and there is a serious unclarity in the notion of calculation or expectation involved in the criterion. These points can perhaps be best made by an example.

We may suppose that a greengrocer unwittingly sells his customer a bad orange, and so (by Aristotle's criterion of intention) unintentionally does him an injury. He need not be dishonest, merely less than completely vigilant: let him be ớveu kakias. But it was not, let us say, an outcome contrary to his expectation or calculation: this sort of thing happens often enough in the greengrocery business, so he is not surprised. Certainly it is plausible to say that the man sold the bad orange by mistake. But suppose all the circumstances the same save that the greengrocer is surprised by what happens: despite its having happened not infrequently in the past, he never 
reckons or expects that it will do so again. According to this version of Daube's Aristotle, the selling of the bad orange will this time not be a mistake but just an accident, a mishap. Yet plainly the single difference between the two cases, if we take it to consist in the presence or absence of surprise, is on any reckoning irrelevant to the question of whether a mistake was committed or not.

1 have used the words 'expectation' and 'calculation' indifferently in presenting this example. But, of course, the difference between them is important here in a way in which it is not for the traditional interpretation. According to the traditional view, Aristotle makes a distinction on the basis of what could or could not reasonably be foreseen; whether one expresses this notion by 'expect' or 'calculate' does not matter. If, however, the distinction is founded not on possibility but on fact, then it is of some importance to know the precise state of mind of the author of an unwitting injury. For the closer the injury approaches to being a calculated risk, an unfortunate but foreseen consequence of a plan, the less sympathetic do we become to the plea that it was just a mistake. If, on the other hand, expectation amounts to little besides not being very surprised in the event, the purity of the agent's intention is not similarly in doubt.

But it is time to examine the version of Daube's interpretation favoured by its author. Again, we may take an example, this time one at the heart of Daube's con-

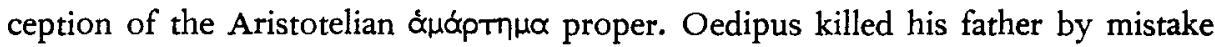
rather than by accident, because although he did not know that the old man at the crossroads was his father, and consequently committed parricide unwittingly, he did intentionally harm someone (if under provocation and hence without vice). In pure accidents no harm whatever is intended. The example is fitted to Aristotle's criterion

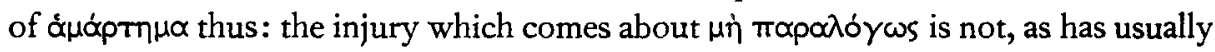
been supposed, the unwitting injury (in this case, parricide), but the intentional injury

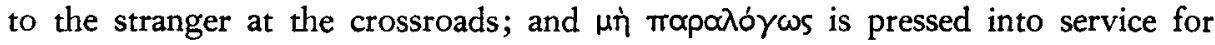
'intended' (cf. pp. 14I, 144, I47-5I).

This account of Aristotle's words is fantastically implausible. For one thing, its relation to the text is acutely uncomfortable. 'Intended' is not a natural translation of

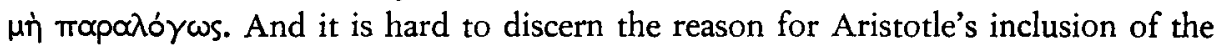
ơvev kakias proviso. What conceivable difference does it make to deciding whether Oedipus killed his father by mistake if he hit out at the man at the crossroads with malice aforethought or not? Daube at one point (p. 134, top) tries to represent ơvev korkias as a consequence of $\mu \varepsilon \tau^{\prime}$ '́rvolas. But this move, suspect in itself, makes Aristotle equivocate on $\beta \lambda \alpha \beta \eta$ : the $\beta \lambda \alpha \beta \eta$ which is intended is the harm to the man at the crossroads, the $\beta \lambda \alpha \beta \eta$ that is without vice is the harm to Oedipus's father, who unknown to him is identical with the man he intentionally harmed. So much for Daube's handling of the text. The logic of his Aristotle's position is no happier. It is not convincing to rule that only persons who intentionally harm others make mistakes. If in a gun shop I pick up what I take to be a toy gun and jokingly shoot you dead with it, that is not just a chapter of accidents.

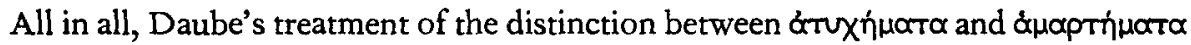
proper leaves much to be desired. But he has posed a question of great interest in 
raising the issue of the role of negligence in Aristotle's thinking on this matter. And while he is wrong to seek to extrude from Aristotle's characterizations of the species

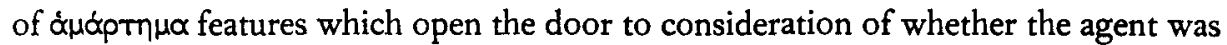
negligent, he is right in maintaining that the notion of negligence does not figure in the further treatment of $\alpha \mu \alpha p т r i \mu_{\alpha} \alpha$ in the context. I am inclined to believe this more significant than the fact that $\mu \eta \dot{\eta} \pi \propto \rho \alpha \lambda{ }^{\prime} \gamma \omega s$ invites us (no more than invites) to ask whether the agent did not take due care. Consequently, I find persuasive Daube's general thesis that Aristotle's discussion here is cast in a conceptual mould altogether different from that which shapes the distinction in Roman law between culpa and sasus, where the criterion of negligence became fundamental (pp. ${ }_{3} \mathrm{I}_{-56} \mathrm{6}$ ).

That there is a very considerable difference in conceptual framework comes out clearly if we ask to what extent and in what way Aristotle would hold those who

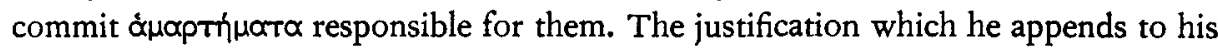

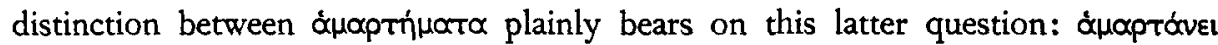

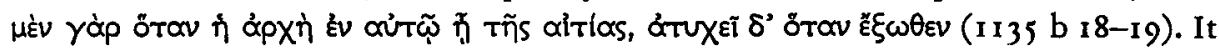
might be argued that a substantial concern with negligence could be attributed to Aristotle in this chapter if we could follow Jackson in reading óyvotas for aitios. For

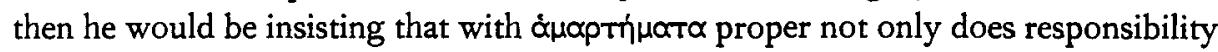
lie with the agent, but the relevant responsibility is responsibility for his own ignorance. And if we accept that it is on this ground ( $\gamma$ óp) that such mistakes are taken to come about not contrary to reasonable expectation, we must infer that the starting point of Aristotle's account is the thought that in these cases the agent is negligent (cf. III 5. III 3 b 30-III4 a 3).

This line of argument should be resisted. Emendation of the MS reading is not necessary; and in proposing arvolas Jackson failed to notice that the distinction

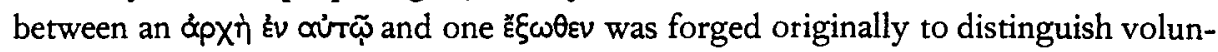

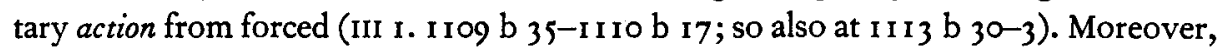
to agree to the inference that Aristotle's eye is fixed on the agent's negligence is to meet embarrassment when we read the last paragraph of the chapter ( 1 I 36 a 5-9), where Aristotle writes as if the only explanations of unintended injuries he is prepared to countenance are that the injury was done not only in ignorance but because of

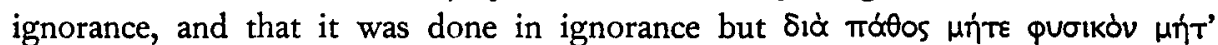

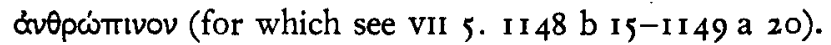

With Burnet, Ross et al. we ought to retain oitios and suppose Aristotle to mean

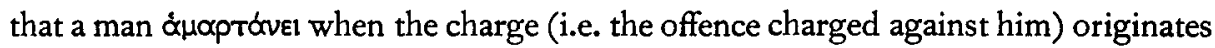
in him, divXei when its origin is external. The point of the remark will have to be merely that the distinction between types of unintended $\beta \lambda \alpha \beta \eta$ is supported by the

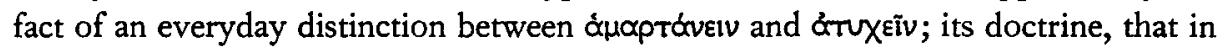
the latter case the man does not contribute the circumstance of central importance to the outcome (his javelin may have hit a bystander, but a freak gust of wind was to blame), whereas in the former, where he can cite no such interfering factor, it is he who is responsible for what happened.

Here, as in his division of explanations of unintended injuries, Aristotle works almost exclusively with the Socratic conceptual equipment employed in the discussion 


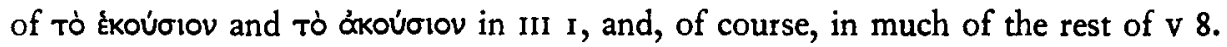
Where we would impute negligence, he sees behaviour which satisfies one criterion

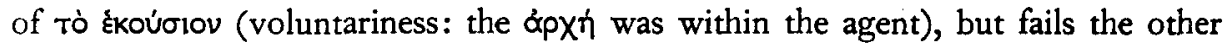
(what is done is not wholly intended: theagent was ignorant). Only with $\mu$ iो $\pi \propto p \alpha \lambda \delta$ ' $\gamma \omega$ s is there a hint of a different viewpoint. Such evidence as we possess suggests, I submit, that it arises not from a belief on Aristotle's part in the central importance of asking whether the agent took due care or not, but rather as an unexplored consequence of

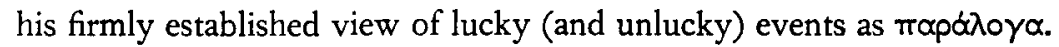

I have restricted discussion to $E N \vee 8$. Elsewhere Aristotle does introduce a con-

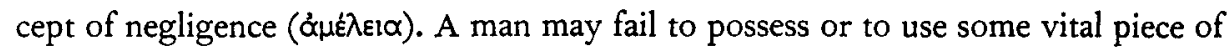
factual information through negligence. In the latter case he is not properly described as ignorant, according to Aristotle; we are presumably supposed to think of him as a fully responsible agent. In the former case he is to blame if the information was easy to come by or something 'necessary' (óvajkoĩov) ( $E E$ II 9. I225 b I I-I6, a passage overlooked by Daube). A closely related text in $E N$ (III 5. I I I 3 b 30-I I I 4 a 3 , unconvincingly discussed by Daube, pp. 137-9, I $45 \mathrm{n}$. 1) makes it fairly plain that the blame attaches first and foremost to the agent's ignorance (he was responsible for taking care to obtain the relevant information); we should infer that Aristotle thinks him responsible for what he did only at this second remove.

It might be thought that we should simply assimilate the author of $\alpha \mu a p$ rínaro proper with the ignorant but negligent man. But negligence is not necessarily ouve kokías; and in any case Aristotle evidently holds it to be a proper reason for punishing someone. If we read I I 36 a 5-9 as an integral part of $E N$ v 8 (and the contrast of a 8-9 with II 35 b 20-2 makes it hard not to do so), we have to take Aristotle as implying

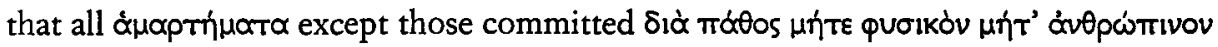
are pardonable.

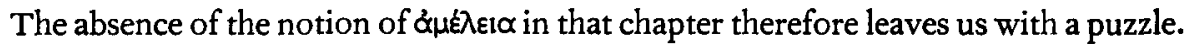
In both his ethical treatises Aristotle recognized the existence and importance of a category of deeds done in ignorance out of negligence - in the earlier $E E$ actually

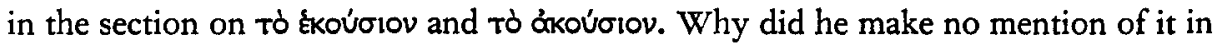
$E N \vee 8$ ?

ST JOHN'S COLLEGE, CAMBRIDGE

M. SCHOFIELD 